\title{
ASSOCIATION OF IRISIN WITH THE OXIDANT-ANTI OXIDANT PARAMETERS IN TYPE 2 DIABETIC PATIENTS ACCORDING TO AGE IN THI-QAR PROVINCE/ IRAQ ${ }^{1}$
}

\author{
Saad H. Al-Badry, Khalid G. Al-Fartoosi \\ Biology Department, College of Science, University of Thi-Qar
}

DOI: $10.37648 /$ ijrst.v10i01.002

Received: 15 ${ }^{\text {th }}$ December, 2019; Accepted:05 ${ }^{\text {th }}$ January, 2020; Published: 02 ${ }^{\text {nd }}$ March, 2020

\begin{abstract}
The present study aimed to assessment of irisin level in patients with the newly onset type 2 "diabetes mellitus" $(T 2 D M)$ and the scanning the association of irisin value with some physiological and oxidant-anti oxidant parameters. This study comprised 60 individuals diagnosed in newly onset T2DM and 40 healthy contributors (control group). Malondialdehyde (MDA), Ceruloplasmin and serum albumin concentration was calculated in patient who involved in this study. Serum irisin levels was evaluated by ELISA kit.

The present study showed a significant increasing $(P \leq 0.05)$ of glycohemoglobin $(H b A 1 C)$ and FBS level in patient with DM2 compared with the control groups $(6.88 \pm 1.02$ vs $4.15 \pm 0.56 ; 7.85 \pm 1.89$ vs $4.94 \pm 0.40)$ respectively. Also, the results explained a significant increased $(P \leq 0.05)$ of $T-C h, T g$ and LDL level in DM2 group compared with the control group $(4.27 \pm 0.90$ vs $4.23 \pm 0.40 ; 2.14 \pm 0.86$ vs $1.89 \pm 0.26 ; 2.84 \pm 0.94$ vs $2.23 \pm 0.52)$ respectively. Whereas, the results showed a significant decrease $(P \leq 0.05)$ of irisin, insulin, $C$-peptide and HLD in DM2 group compared with the control group $(22.32 \pm 4.55$ vs $27.81 \pm 2.93$; $18.29 \pm 3.66$ vs $27.27 \pm 6.90$; $3.12 \pm$ 0.99 vs $6.03 \pm 0.48 ; 1.0 \pm 0.17$ vs $1.61 \pm 0.37)$ respectively.

In correlation analysis the results showed a negative association between irisin and (HbAlc) $(r=-0.152)$, glucose $(r=-0.331)$, insulin $(r=-0.156), H D L(r=-0.114)$ and BMI $(r=-0.219)$. Whereas, the results showed positive correlation between irisin and IL-6 $(r=0.0 .115), C R P(r=0.153)$, C-peptide $(r=0.013), T-C h(r=0.057)$, $\operatorname{Tg}(r=0.209)$ and $\operatorname{LDL}(r=0.035)$.
\end{abstract}

Conclusion

1- The level of irisin in the type 2 patients reduced with high level of HOMA-IR and BMI.

\footnotetext{
${ }^{1}$ How to cite the article: Al-Badry S.H., Al-Fartoosi K.G., Association of Irisin With the Oxidant-Antioxidant Parameters in Type 2 Diabetic Patients According to Age in Thi-Qar Province, Iraq, IJRST, Jan-Mar 2020, Vol 10, Issue 1, 10-19, DOI: http://doi.org/10.37648/ijrst.v10i01.002
} 
2- From the results of correlation analysis between irisin and oxidant factors we can concluded that irisin work as $a$ anti agents of the oxidative condition.

3-The negative correlation between irisin and glucose refer to the important of it on the glucose homeostasis. Keywords: Irisin, T2DM, inflammatory parameters.

\section{INTRODUCTION}

Diabetes mellitus (DM) is the continual disease common characterizes by hyperglycemia resulting from defects in secretion and/or its activity of insulin (WHO, 2016), its frequency elevate regularly every year. The universal commonness of diabetes, amongst adults were $6.4 \%$, affecting 285 million patients in 2010, and is probable to augment to $7.7 \%$ (i.e., 439 million individuals) in 2030.

In humans, irisin is produced mainly by skeletal muscle in response to physical activity. It has been demonstrated that irisin plays a pivotal role in inducing fat browning and regulating energy expenditure. New findings from various studies conducted in both animals and humans suggest that irisin can affect bone and glucose metabolism. In particular, irisin is able to increase bone cortical mass by stimulating the osteoblast pathways, and irisin levels are inversely correlated with the incidence of fragility fractures among postmenopausal women affected by osteoporosis. Most available evidence shows that irisin significantly influences glucose and energy homeostasis (Endocrinologica, 2017).Bostrom et al., (2012) identified the irisin, an energetic metabolism-related myokine. Its secretion involves the increase of peroxisome proliferator- activated receptor-gamma coactivator 1 alpha (PGC1 alpha) in the muscle, inducted by exercise, promoting the expression and proteolysis cleavage of Fndc5, a type 1 membrane protein "fibronectin type III domaincontaining protein 5 ", with release the irisin fragment for the blood flow, this hormone promotes a browning process on the white adipose tissue, a encoding for the thermo genesis in the tissue cells, through the increase of the mitochondrial uncoupling protein 1 (UCP1). So, the final effect of the hormonal signal promoted by the irisin is an enlarge on the physical energy spending, with the decrease of the obesity and development on the insulin resistance caused by diet (Bostrom et al., 2012).

Some new studies have shown that the irisin values were lesser in patients with T2DM when compared with the non-diabetics (Arias-Loste et al., 2014), perhaps for a lacking expression of PGC1 alpha in the muscle (Liuet al., 2013). So, part of the diabetic subjects used a variety of medications. This variation also found on other forms of diabetes, like the type 1 diabetes mellitus (T1DM) (Espes and Arlsson, 2015), and gestational diabetes mellitus (GDM) (Ebertet al., 2014). In addition, increases levels of irisin are also linked with other metabolic parameters such as body mass index (BMI), $2 \mathrm{~h}$ plasma glucose after OGTT "(oral glucose tolerance test)", HbA1c and triglycerides (Choiet al., 2013). Numerous studies have addressed the relationship between low of serum irisin levels and insulin resistance or diabetes. A lot of studies showed lower circulating irisin levels in type 2 diabetic patients (Zhanget al., 2016), and others explained a negative correlation with fasting glucose in blood and $\mathrm{HbA1c}$ (Yan et al., 2014).

This study aimed to measurement of irisin level in patients with newly onset- T2DM and to examine the association between irisin level and glycemic indices (BMI, fasting blood glucose, fasting insulin, Cpeptide and lipid profile and some Oxidative Stress antioxidant parameter).

\section{MATERIAL AND METHODS}

\section{1 .Subjects}

The aimed population of this study was 60 male persons who are already diagnosed as new onset of T2 DM., which referred to the Nasiriyah Endocrine and Diabetes Centre in Thi-Qar province, Iraq during February - August 2018. The patients are diagnosed as newly onset by the consultant medical staff, according to checked clinical examination and biochemical analysis. Another group of apparently healthy

\section{INTERNATIONAL JOURNAL OF RESEARCH IN SCIENCE AND TECHNOLOGY}


individuals represented as the control group. The data was obtained from each patient including ages, BMI, medications, other disease, any other chronic disease and medical history. The patients were 60 males and the control grope involved 40 males individuals divided in to tow parts GI 35-45, GII 46-55 years old matched with age in type 2 group .

\subsubsection{Blood collection}

About $(5 \mathrm{~mL})$ of fasting venous sample of T2DM patients and controls divided to two parts the first part was $(2 \mathrm{ml})$ putting in tube with anti-conglutination (EDTA tube) this used to determination of HbA1C test, and the second part was $(3 \mathrm{ml})$ to obtain of serum.

\subsection{Evaluation of Body Mass Index (BMI)}

"Body mass index (BMI)" is a determine of someone's weight in linked to their height, and then we put these measurements in the equation:

$\mathrm{BMI}=$ Weight $(\mathrm{kg}) /$ Height $(\mathrm{m})^{2}$ (Nuttall, 2015).

\subsection{Biochemical parameters analysis}

\subsubsection{Hormones}

The irisin, insulin and C-peptide hormone, concentration was calculated match up with to the ELIZA., based on the sandwich principle (Miyazawaet al.,1999).

\subsubsection{Biochemical parameters}

\subsubsection{Evaluation of fasting blood sugar (F.B.S)}

Glucose was determined after enzymatic oxidation in the presence of glucose oxidase. The hydrogen peroxide formed reacts under catalysis of peroxidase, with phenol and 4aminophenazone to form a red-violet quinonimine dye as indicator (Trinder, 1969).

\subsubsection{2.}

HbA1C

test

System reagents for the quantitative determination of HbA1c (Hemoglobin A1c), in human blood, on Beckman Coulter AU analyzers (Jeppssonet al., 2002).

\subsubsection{Serum cholesterol and Triglyceride}

Enzymatic method described by Allain et al., (1974).
Cholesterol esters $\rightarrow$ cholesterol + free fatty acids

Cholesterol $+\mathrm{O}_{2} \rightarrow$ cholestero 4 one $3+\mathrm{H}_{2} \mathrm{O}_{2}$

$2 \mathrm{H}_{2} \mathrm{O}_{2}+$ phenol $+\mathrm{PAP} \rightarrow$ Quinoneimine $($ pink $)+2 \mathrm{H}_{2} \mathrm{O}$.

Evaluation of" High density lipoprotein" ( HDL) 2.3.2.4.

The chemical substances only for healing of specimen previous to calculate of HDL.,- $\mathrm{C}$ add to reagent for sum cholesterol. "Low density lipoproteins (LDL) very low density (VLDL) " and "chylomicrons" from specimen are precipitate by "phosphotungstic acid (PTA) and magnesium chloride". HDL.,C obtained floating following of centrifuged, so then calculated add to sum cholesterol (Badimon et al., 1990).

\subsubsection{Evaluation of" Low density lipid protein" (L D L) \\ By the following function (Peter and Kwiterovich, 2004).

$$
\begin{aligned}
& L D L=\text { Cholesterol con. }-(T g \backslash 5)-H D L \\
& \text { con. }=(\mathrm{mmol} / \mathrm{L})
\end{aligned}
$$

\subsubsection{Determination. of oxidant-antioxidant. stress}

2.3.4.1. Determination. of serum. malondialdehyde:

Lipid peroxidation items were one of the key pointers of oxidative pressure. Lipid peroxidation was dictated by utilizing the thiobarbituric corrosive technique (Fong et al., 1973).

\subsubsection{Determination. of ceruloplasmin concentrations}

Ceruloplasmin focus in serum was estimated by Menden et al., 1977.

\subsection{Statistical Analysis}

All statistical analysis was performed by using the Statistical Package Social Sciences version 20 software (SPSS v.20) for Windows, due to sample Ttest. 


\section{RESULTS}

\subsection{BMI}

The present study showed a significant increase $(\mathrm{P}$ $\leq 0.05)$ of BMI level in patient with DM2 compared with the control group $(25.83 \pm 2.13$ vs $21.82 \pm 1.65)$ (table 2.1).

\subsection{Biochemical parameters}

The present study showed a significant increase $(\mathrm{P} \leq$ 0.05) of glycohemoglobin (HbA1C) and FBS level in patient with DM2 compared with the control group $(6.88 \pm 1.02$ vs $4.15 \pm 0.56 ; 7.85 \pm 1.89$ vs $4.94 \pm 0.40)$ respectively (table 2.1). Also, the results explained a significant increased $(\mathrm{P} \leq 0.05)$ of $\mathrm{T}-\mathrm{Ch}, \mathrm{Tg}$ and LDL level in DM2 group compared with the control group $(4.27 \pm 0.90$ vs $4.23 \pm 0.40 ; 2.14 \pm 0.86$ vs $1.89 \pm$ $0.26 ; 2.84 \pm 0.94$ vs $2.23 \pm 0.52$ ) respectively. Whereas, the results showed a significant decrease ( $\mathrm{P}$ $\leq 0.05)$ of irisin, insulin, C-peptide and HLD in DM2 group compared with the control group $(22.32 \pm 4.55$ vs $27.81 \pm 2.93 ; 18.29 \pm 3.66$ vs $27.27 \pm 6.90 ; 3.12 \pm$ 0.99 vs $6.03 \pm 0.48 ; 1.0 \pm 0.17$ vs $1.61 \pm 0.37)$ respectively (table 2.2 ).

\subsection{Oxidative Stress - antioxidant parameter}

$\begin{array}{llll}\text { 4.3.1 } \quad \text { Lipid } & \text { Peroxidation } & \text { Status } \\ \text { (Malondialdehyde) } & & \end{array}$

The present study showed a significant. increase in the concentration of serum MDA in patients $(p \leq .0 .05))$ compared. with group of control (Table 2.1).

\subsubsection{Ceruloplasmin Concentrations}

The present study showing a significant elevation in $\mathrm{Cp}$ levels in patients compared with control group $(\mathrm{P} \leq .0 .05)$.

\subsection{Correlation analysis}

In correlation analysis the results showed a negative association between irisin and (HbA1c) $(r=$ -0.152 ), hyperglycemia $(r=-0.331)$, insulin $(r=-$ 0.156), $\operatorname{HDL}(\mathrm{r}=-0.114)$ and BMI $(\mathrm{r}=-0.219)$. Whereas, the results showed positive correlation between irisin and IL-6 ( $\mathrm{r}=0$. 0.115), CRP ( $\mathrm{r}=$ 0.153), C-peptide ( $\mathrm{r}=0.013), \mathrm{T}-\mathrm{Ch}(\mathrm{r}=0.057), \mathrm{Tg}$ $(\mathrm{r}=0.209)$ and $\operatorname{LDL}(\mathrm{r}=0.035)$ (Table 2.3).

Table (2.1): Level of hormonal, physiological and oxidative stress - antioxidant parameter parameters in type 2 DM.

\begin{tabular}{|c|c|c|c|c|c|}
\hline Parameters & $\begin{array}{l}\text { GI } \\
N=60\end{array}$ & $\begin{array}{l}\text { GII } \\
N=60\end{array}$ & $\begin{array}{l}\text { Control I } \\
\mathrm{N}=20\end{array}$ & $\begin{array}{l}\text { Control II } \\
\mathrm{N}=\mathbf{2 0}\end{array}$ & $\overline{~ L S D ~}$ \\
\hline BMI & $22.67 \pm 1.458$ & $23.41 \pm 0.62$ & $21.48 \pm 1.29$ & $22.11 \pm 1.456$ & 0.51 \\
\hline $\begin{array}{l}\text { FBG } \\
(\mathrm{mmol} / \mathrm{L})\end{array}$ & $7.87 \pm 1.93$ & $12.97 \pm 0.90$ & 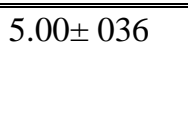 & $4.88 \pm 0.44$ & 0.53 \\
\hline $\begin{array}{l}\text { HbA1C } \\
(\mathrm{mmol} / \mathrm{L})\end{array}$ & $6.92 \pm 1.02$ & $10.72 \pm 1.11$ & $4.143 \pm 0.52$ & $24.149 \pm 0.60$ & 0.39 \\
\hline $\begin{array}{l}\text { Irisin } \\
\text { ng/dl }\end{array}$ & $22.09 \pm 3.69$ & $20.87 \pm 2.48$ & $26.23 \pm 1.72$ & $28.10 \pm 2.57$ & 1.21 \\
\hline
\end{tabular}




\begin{tabular}{|l||l||l|l||l||l||}
\hline Insulin & $18.05 \pm 3.77$ & $16.63 \pm 2.11$ & $26.91 \pm 8.65$ & $28.19 \pm 5.81$ & 2.08 \\
\hline C-peptide & $3.22 \pm 1.15$ & $2.59 \pm 0.93$ & $6.15 \pm 0.45$ & $5.94 \pm 0.49$ & 0.38 \\
\hline MDA & $2.74 \pm 0.45$ & $3.30 \pm 0.40$ & $1.84 \pm 0.35$ & $1.70 \pm 0.30$ & 0.17 \\
\hline Ceruloplasmin & $7.66 \pm 1.57$ & $6.01 \pm 0.82$ & $2.78 \pm 0.89$ & $2.50 \pm 0.52$ & 0.47 \\
\hline
\end{tabular}

Table (2.2): Level of lipid profile parameters in Type 2 DM.

\begin{tabular}{|c|c|c|c|c|c|}
\hline Parameters & $\begin{array}{l}\text { GI } \\
N=60\end{array}$ & $\begin{array}{l}\text { GII } \\
N=60\end{array}$ & $\begin{array}{l}\text { Control I } \\
\mathbf{N}=\mathbf{2 0}\end{array}$ & $\begin{array}{l}\text { Control II } \\
\mathrm{N}=20\end{array}$ & LSD \\
\hline $\begin{array}{l}\text { TG } \\
(\mathrm{mmmol} / \mathrm{L})\end{array}$ & $1.40 \pm 0.20$ & $1.54 \pm 0.21$ & $1.42 \pm 0.29$ & $1.61 \pm 0.38$ & 0.11 \\
\hline T-Ch (mmol/L) & $3.72 \pm 0.486$ & $3.73 \pm 0.479$ & $3.95 \pm 0.474$ & $3.97 \pm 0.471$ & 0.20 \\
\hline $\begin{array}{l}\text { HDL- } \\
\mathrm{Ch}(\mathrm{mmol} / \mathrm{L})\end{array}$ & $1.06 \pm 0.16$ & 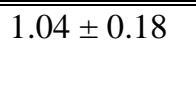 & " $1.51 \pm 0.38$ & $1.54 \pm 0.36$ & 0.10 \\
\hline $\begin{array}{l}\mathrm{LDL} \\
(\mathrm{mmol} / \mathrm{L})\end{array}$ & $2.37 \pm 0.58$ & $2.38 \pm 0.60$ & $2.15 \pm 0.43$ & $2.11 \pm 0.45^{\mathrm{b}}$ & 0.23 \\
\hline
\end{tabular}

Table(2.3): Correlation analysis between irisin and other parameters.

\begin{tabular}{|c|c|c|c|c|c|c|c|c|c|c|c|c|c|}
\hline \multirow{4}{*}{ Irisin } & & Irisin & $\mid \begin{array}{l}\text { C_peptid } \\
\text { e }\end{array}$ & Insulin & MDA & CP & FBS & HbA1c & Chol & TGs & HDL & LDL & BMI \\
\hline & $\begin{array}{l}\text { Correlatio } \\
\text { n }\end{array}$ & 1 & 0.013 & -0.156 & 0.063 & 0.428 & $-0.331^{* * *}$ & -0.152 & 0.057 & 0.209 & -0.114 & 0.035 & -0.219 \\
\hline & Sig. & & 0.922 & 0.234 & 0.428 & 0.634 & 0.010 & 0.246 & 0.667 & 0.108 & 0.384 & 0.789 & 0.093 \\
\hline & $\mathbf{N}$ & 60 & 60 & 60 & 60 & 60 & 60 & 60 & 60 & 60 & 60 & 60 & 60 \\
\hline
\end{tabular}

$(* *=$ significant $)$. 


\section{DISCUSSION}

\section{Biochemical parameters Glycohemoglobin (HbA1c)}

The results explain an important elevated in levels of HbA1c in DM2 compared with the control group, that is might be most exactly reflects the preceding 2-3 months of glycemic control, thus the patient with 2-3 months period of DM., and bad organize to the disease so this situation lead to highly level of HbA1c in blood (Harris, 1998). The high level of $\mathrm{HbA} 1 \mathrm{C}$ in this study was coordinated with other study by Kamran (2010) who reported the bad control to the long period as 2-3 months to the DM disease lead to higher $\mathrm{HbA1c}$ levels and diabetic difficulty (Kamran, 2010). This study showed a negative association among irisin with hemoglobin A1C (HbA1c). Thus, level of irisin might reveal the metabolic condition of patients suffer as of metabolic disorders. In adding to glycemic or $\mathrm{HbA} 1 \mathrm{c}$, "irisinemia" can also grow to be a new gifted idea to observe disorders of metabolism like obesity or $\mathrm{T} 2 \mathrm{DM}$ in future might be appear for a useful means in organization of metabolic diseases (Sanchis et al., 2012).

A negative association has been shown in this study to the irisin values with insulin and HOMA-IR, this might be of all individuals in this study were health with BMI., (At the time indicated by the results of BMI in this study, which observing that it is within the standard range due to the World Health Organization. Association among irisin with insulin resistances confirming by the hypothesized participation of the "p-38-PGC1a- betatrophin pathway of irisin" (Sanchis-Gomar and Perez-Quilis 2014).

\section{Blood glucose}

The results showed a significant raise of blood sugar in DM2 compared with the control group. The confusion of beta cells in pancreas organ lead to reduce production of insulin hormone, if beta cells don't make sufficient insulin, glucose accumulation in the blood in its place when absorbing by cells of the body, pre-diabetes or diabetes might be take place in this condition. The cells of body are hungry of energy in spite of high blood glucose levels in diabetes condition (Forouhi and Wareham, 2014).

\section{Irisin}

Decreased of irisin level were observed in the DM2 compared with the control group, this might be because of the information that irisin was progressively reduced with decrease tolerance of glucose in quantity to insulin resistance or due to a high of fat at the expenditure of muscle mass for require of activity in patients with type2 DM, this explanation matched with the study which done by (Yan et al., 2014; Assyov et al., 2016).

So the irisin and myonectin, ruling by insulin resistance. Irisin and myonectin, are possible involved, in lipid and glucose metabolism, and thus possibly will be stop the development, of insulin resistance. on the other hand, their secretion could also be influence by the enlargement of muscle insulin resistance.

Since irisin and myonectin showing to act in the adipose tissue, their deregulation might have an effect on the crosstalk between the tissues and further has a say to insulin resistance and impair glucose and lipid metabolism. Numerous studies found lesser circulating irisin levels in type 2 diabetic patients (Moreno-Navarrete et al.,2013; Zhang et al., 2014; Zhang et al., 2016).

\section{Lipid profile}

The results showed a significant increase in (triglyceride and Low density lipoprotein ) of new onset patients. Typically, the dyslipidemia is reflected largely in enlarged serum levels of triglycerides and low levels of HDL, cholesterol levels may be very high in proteinuria patients (Schofield et al., 2016). These results are corresponding with the result of Vaziri, (2003).

The model of dyslipidemia, in diabetes is different, from that in non-diabetic people. This explain the significance of lipid and lipoprotein 
examination in diabetic patients and recommend a different lipid lowering agents from that used in nondiabetic population (Rustemeijer et al., 1997). Accordingly, this study showed a negative association between irisin and cholesterol, might be that irisin possibly will inhibit the production of hepatic cholesterol through "AMPK-dependent inhibition of sterol regulatory element-binding proteins (SREBP2) and downstream of its genes target. Obstruction of irisin-induced adenosine monophosphate-activated protein kinase (AMPK) activation by complex C., or knockdown of "AMPK $\alpha 1 "$ (Xiong et al., 2015).

\section{C-Peptide}

The necessary role of C-peptide is a helpful and broadly use method of assess pancreatic beta cell purpose (Jones and Hattersley, 2013; Leighton et al., 2017), not as good as C-peptide levels have been linked with lesser glycemic organize and for this reason elevated HbA1c values (Lachin et al., 2014; Kuhtreiber et al., 2015). Decreases value of Cpeptide and decrease beta cell function has been related to bigger levels of glucose change capability (Kramer et al., 2014; Hope et al., 2016).

\section{Insulin}

In study by Fukushima et al., 2016 in obese patients create the positive correlation between irisin and insulin resistance (Fukushima et al., 2016), Though others reported either no association (Liu et al., 2013; Choi et al., 2013) or even a negative relationship

(Yan et al.,2014) among serum irisin with homeostatic model assessment of insulin resistance (HOMA-IR) score. Level of irisin was negative associated with BMI and insulin in our study individuals, this could be showed by the fact that all participants in our study were metabolically in good physical shape with BMI (At the time indicated by the results of BMI in our study, which showed that it is within the normal range according to the World Health Organization), table 2.

\section{Oxidant- antioxidant system}

\section{Oxidant system}

\section{MDA}

From our results we observed elevated MDA level in DM2 compared with the control grope, Because of oxidative stress results from an inequity between radical- formation and radical-scavenging systems, i.e. amplified free radical making or lowering activity of antioxidant defenses, or both. Hyperglycemiaactivate oxidative stress has also been linked with enlarged endothelial cell apoptosis in vitro and in vivo (Bajaj and Khan, 2012). Several studies have shown that DM(types 1 and 2) is accompanied by elevate structuring of free radicals and looser antioxidant capacity, leading to oxidative injure of cell components (Bashan et al.,2009).

There are numerous sources of "reactive oxygen species (ROS)" manufacture in diabetes including those of mitochondrial and non-mitochondrial origins; ROS accelerate the four important molecular mechanisms involved in "hyperglycemia-induced oxidative tissue harm., these four pathways are activation of "protein kinase C (PKC)", "enlarged hexosamine pathway flux, increased advanced glycation end-product (AGE), and increased polyol pathway flux (Roloand Palmeira, 2006).

\section{Ceruloplasmin}

Ceruloplasmin was elevated in diabetic group than non-diabetic group. like result has found, in different studies manage by (Lee et al., 2015, Sharma et al., 2018).The possible clarification could be that highest level of ceruloplasmin in pre-diabetic group but does not fluctuate significantly in the diabetic range. Similarly, considering both groups ceruloplasmin linked with "age, fasting glucose, post prandial glucose, glycated hemoglobin, triglycerides and TG/HDL-C ratio. Thus, it implies, that serum triglycerides, and TG/HDL-C rang which are substitute, indicator of insulin resistance might, be reflect by ceruloplasmin. Ceruloplasmin could be used as substitute to mark, the insulin resistance (Sharma et al., 2018). Cells have evolved highly

\section{INTERNATIONAL JOURNAL OF RESEARCH IN SCIENCE AND TECHNOLOGY}


complex enzymatic and non-enzymatic antioxidant systems, which work synergistically, and in combination with each other, to protect the body against free radical-induced damage (Bajaj and Khan, 2012). In patients with T2DM, the content of oxidized fatty acids is increased, and the antiinflammatory and antioxidant activities of HDLs are impaired (Morgantini et al., 2011). In other study suggested of The increased, glucose for the long period of time without controlled is one of the motivation factors, for malignancy, the insulin resistance and the unbalanced lipid profile additionally increase the risks, thus, enlarged ceruloplasmin level in diabetic patients can be show the risk of malignancy (Ryu and Park, Scherer, 2014).

So, level of ceruloplasmin, which is considered as a very, important inflammatory marker, enlarged

\section{REFERENCES}

[1] Allian, C.C.; Poon, L.S.; Chan, C.S.; Richmond, W. and FU, P.C. (1974) "Enzymatic Determination of Total Serum Cholesterol." Clinical Chem. 20, (4): 470-75.

[2] Arias-Loste, M. T., Ranchal, I., Romero-Gómez, M., and Crespo, J. (2014). Irisin, a link among fatty liver disease, physical inactivity and insulin resistance. International journal of molecular sciences, 15(12), 23163-23178.

[3] Assyov Y., Gateva A., Tsakova A., Kamenov Z. (2016).Irisin in glucose continuum. Exp. Clin. Endocrinol. Diabetes; 124: 22-27.

[4] Badimon, J. J., Badimon, L., \& Fuster, V. (1990). Regression of atherosclerotic lesions by high density lipoprotein plasma fraction in the cholesterol-fed rabbit. The Journal of clinical investigation, 85(4), 12341241.

[5] Bains, S., Anyaeche, C., Wyatt, A., Coker, O., \& Bolodeoku, J. (2017). Evaluation of Point of Care Test (POCT), i-CHROMATM Serum C-Reactive Protein (CRP) Assay and Microalbumin Urine (MAU) Methods. Annals of Clinical and Laboratory Research, 5(3), 192.

[6] Bajaj, S., and Khan, A. (2012). Antioxidants and diabetes. Indian journal of endocrinology and metabolism, 16(Suppl 2), S267.

[7] Bashan, N.; Kovsan, J.; Kachko, I.; Ovadia, H.; and Rudich, A. (2009). Positive and negative regulation of insulin signaling by reactive oxygen and nitrogen species. Physiological Reviews, 89(1), $27-71$.

[8] Boström, P., Wu, J., Jedrychowski, M. P., Korde, A., Ye, L., Lo, J. C., and Kajimura, S. (2012). A PGC1- $\alpha-$ dependent myokine that drives brown-fat-like development of white fat and thermogenesis. Nature, 481(7382), 4638.

[9] Choi, Y. K., Kim, M. K., Bae, K. H., Seo, H. A., Jeong, J. Y., Lee, W. K., and Park, K. G. (2013). Serum irisin levels in new-onset type 2diabetes. Diabetes research and clinical practice, 100(1), 96-101.

[10] De Feo, P.; Volpi, E.; Lucidi, P.; Cruciani, G.; Reboldi, G.; Siepi, D., and Bolli, G. B. (1993). Physiological increments in plasma insulin concentrations have selective and different effects on synthesis of hepatic proteins in normal humans. Diabetes, 42(7), 995-1002.

\section{INTERNATIONAL JOURNAL OF RESEARCH IN SCIENCE AND TECHNOLOGY}


[11] Ebert, T., Focke, D., Petroff, D., Wurst, U., Richter, J., Bachmann, A., and Bast, I. (2014). Serum levels of the myokine irisin in relation to metabolic and renal function. European journal of endocrinology, 170(4), 501-506.

[12] Endocrinologica, M. (2017). Irisin as a regulator of bone and glucose metabolism: a narrative review. Minerva endocrinologica.

[13] Espes, D., Lau, J., and Carlsson, P. O. (2015). Increased levels of irisin in people with long-standing Type 1 diabetes. Diabetic medicine, 32(9), 1172-1176.

[14] Fong, K. L.; McCay, P. B.; Poyer, J. L.; Keele, B. B., and Misra, H. (1973). Evidence that peroxidation of lysosomal membranes is initiated by hydroxyl free radicals produced during flavin enzyme activity. Journal of Biological Chemistry, 248(22), 7792-7797.

[15] Forouhi, N. G., \& Wareham, N. J. (2014). Epidemiology of diabetes. Medicine (Abingdon). 42 (12): $\quad 698-702$.

[16] Fukushima, Y., Kurose, S., Shinno, H., Cao Thi Thu, H., Tamanoi, A., Tsutsumi, H., and Kimura, Y. (2016). Relationships between serum irisin levels and metabolic parameters in Japanese patients with obesity. Obesity science \& practice, 2(2), 203-209.

[17] Goldstein, J. L., Ho, Y. K., Basu, S. K., \& Brown, M. S. (1979). Binding site on macrophages that mediates uptake and degradation of acetylated low density lipoprotein, producing massive cholesterol deposition. Proceedings of the National Academy of Sciences, 76(1), 333-337.

[18] Harris, M. I. (1998). Diabetes in America: epidemiology and scope of the problem. Diabetes care, 21(Supplement 3), C11-C14.

[19] Hope, S. V., Knight, B. A., Shields, B. M., Strain, W. D., Hattersley, A. T., Choudhary, P., and Jones, A. G. (2016). Low c-peptide is associated with high glycemic variability and hypoglycemia in insulin-treated patients with type 2 diabetes. Diabet Med, 33, 144.

[20] Jeppsson, J. O., Kobold, U., Barr, J., Finke, A., Hoelzel, W., Hoshino, T., ... \& Thienpont, L. (2002). Approved IFCC reference method for the measurement of HbA1c in human blood. Clinical chemistry and laboratory medicine, 40(1), 78-89.

[21] Jones, A. G., and Hattersley, A. T. (2013). The clinical utility of C-peptide measurement in the care of patients with diabetes. Diabetic Medicine, 30(7), 803-817.

[22] Kamran M. A. (2010). Association between high risk foot, retinopathy and hba1c in Saudi diabetic population. Pak J Physiol., 622-28.

[23] Kramer, C. K., Choi, H., Zinman, B., and Retnakaran, R. (2014). Glycemic variability in patients with early type 2 diabetes: the impact of improvement in $\beta$-cell function. Diabetes Care, DC_132591.

[24] Kuhtreiber, W. M., Washer, S. L. L., Hsu, E., Zhao, M., Reinhold III, P., Burger, D and Faustman, D. L. (2015). Low levels of C-peptide have clinical significance for established Type 1 diabetes. Diabetic Medicine, 32(10), 13461353.

[25] Lachin, J. M., McGee, P., Palmer, J. P., and DCCT/EDIC research group. (2014). Impact of C-peptide preservation on metabolic and clinical outcomes in the Diabetes Control and Complications Trial. Diabetes, 63(2), 739-748.

[26] Lee, H. J.; Lee, J. O.; Kim, N.; Kim, J. K.; Kim, H. I.; Lee, Y. W., and Hwang, S. (2015). Irisin, a novel myokine, regulates glucose uptake in skeletal muscle cells via AMPK. Molecular Endocrinology, 29(6), 873-881.

[27] Leighton, E., Sainsbury, C. A., and Jones, G. C. (2017). A practical review of C-peptide testing in diabetes. Diabetes therapy, 8(3), 475-487.

[28] Liu, J. J., Wong, M. D., Toy, W. C., Tan, C. S., Liu, S., Ng, X. W., .and Lim, S. C. (2013). Lower circulating irisin is associated with type 2 diabetes mellitus. Journal of Diabetes and its Complications, 27(4), 365-369.

[29] McMillan, D. E. (1989). Increased levels of acute-phase serum proteins in diabetes. Metabolism, 38(11), 1042-1046.

[30] Menden, E. E.; Boiano, J. M.; Murthy, L., and Petering, H. G. (1977). Modification of a P-Phenylenediamine Oxidase Method to Permit Non-Automated Ceruloplasmin Determinations in Batches of Rat Serum or Plasma Microsamples. Analytical Letters, 10(3), 197-204.

\section{INTERNATIONAL JOURNAL OF RESEARCH IN SCIENCE AND TECHNOLOGY}


[31] Miyazawa, H., Bannai, H., Yanase, T., Morita, C., Satoh, S., Sugiyama, J., ... \& Inouye, S. (1999). A reversesandwich enzyme-linked immunosorbent assay for verocytotoxin 1 and 2 antibodies in human and bovine sera. Clin. Diagn. Lab. Immunol., 6(5), 701-704.

[32] Moreno-Navarrete, J. M., Ortega, F., Serrano, M., Guerra, E., Pardo, G., Tinahones, F., and Fernández-Real, J. M. (2013). Irisin is expressed and produced by human muscle and adipose tissue in association with obesity and insulin resistance. The Journal of Clinical Endocrinology \& Metabolism, 98(4), E769-E778.

[33] Morgantini, C.; Natali, A.; Boldrini, B.; Imaizumi, S.; Navab, M.; Fogelman, A. M., and Reddy, S. T. (2011). Antiinflammatory and antioxidant properties of HDLs are impaired in type 2 diabetes. Diabetes, DB_110378.

[34] Nuttall, F. Q. (2015). Body mass index: obesity, BMI, and health: a critical review. Nutrition today, 50(3), 11.

[35] Peter O. and Kwiterovich, Jr., M.D. (2004). Diagnostics, R., \& Diagnostics, B. M. Laboratory Procedure Manual. Laboratory Procedure Manual, 410-614-1030.

[36] Rolo, A. P., and Palmeira, C. M. (2006). Diabetes and mitochondrial function: role of hyperglycemia and oxidative stress. Toxicology and Applied Pharmacology, 212(2), 167-178.

[37] Rustemeijer, C .; Schouten, J. A .; Janssen, E. N .; Spooren, P. F . and Van Doormaal, J. J. (1997). Pravastatin in diabetes associated hypercholesterolemia. Acta. diabetol., 34(4): 294-300.

[38] Ryu, T. Y.; Park, J., and Scherer, P. E. (2014). Hyperglycemia as a risk factor for cancer progression. Diabetes \& Metabolism Journal, 38(5), 330-336.

[39] Sanchis-Gomar, F., \& Perez-Quilis, C. (2014). The p38-PGC-1 $\alpha$-irisin-betatrophin axis: Exploring new pathways in insulin resistance. Adipocyte, 3(1), 67-68.

[40] Sanchis-Gomar, F., Lippi, G., Mayero, S., Perez-Quilis, C., \& García-Giménez, J. L. (2012). Irisin: a new potential hormonal target for the treatment of obesity and type 2 diabetes. Journal of diabetes, 4(3), 196-196.

[41] Schofield, J. D., Liu, Y., Rao-Balakrishna, P., Malik, R. A., \& Soran, H. (2016). Diabetes dyslipidemia. Diabetes Therapy, 7(2), 203-219.

[42] Trinder, P. (1969). Determination of glucose in blood using glucose oxidase with an alternative oxygen acceptor. Annals of clinical Biochemistry, 6(1), 24-27.

[43] Vaziri, N. D.; Sato, T. and Liang, K.(2003). Molecular mechanism of expressed and produced by human muscle and adipose tissue in association with obesity and insulin resistance. hypercholesterolemia. Acta. diabetol., 34(4): 294300 .

[44] World Health Organization. (2016). World health statistics 2016: monitoring health for the SDGs sustainable development goals. World Health. Organization.

[45] Xiong, X. Q., Chen, D., Sun, H. J., Ding, L., Wang, J. J., Chen, Q., and Gao, X. Y. (2015). FNDC5 overexpression and irisin ameliorate glucose/lipid metabolic derangements and enhance lipolysis in obesity. Biochimica et Biophysica Acta (BBA)-Molecular Basis of Disease, 1852(9), 1867-1875.

[46] Yan, B.; Shi, X.; Zhang, H.; Pan, L. and Ma, Z. et al. (2014). Association of Serum Irisin with Metabolic Syndrome in Obese Chinese Adults. PLoS ONE., 9(4).

[47] Zhang, C., Ding, Z., Lv, G., Li, J., Zhou, P., \& Zhang, J. (2016). Lower irisin level in patients with type 2 diabetes mellitus: A case-control study and meta-analysis meta. Journal of diabetes, 8(1), 56-62.

[48] Zhang, M., Chen, P., Chen, S., Sun, Q., Zeng, Q. C., Chen, J. Y., and Wang, J. K. (2014). The association of new inflammatory markers with type 2 diabetes mellitus and macrovascular complications: a preliminary study. Eur Rev Med Pharmacol Sci, 18(11), 1567-72.

\section{INTERNATIONAL JOURNAL OF RESEARCH IN SCIENCE AND TECHNOLOGY}

